\title{
Analysis and design of single phase voltage-frequency converter with optimized PI controller
}

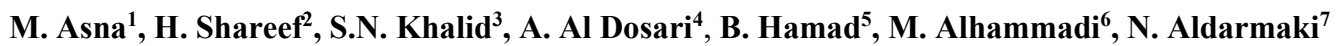 \\ $1,2,4,5,6,7$ Department of Electrical Engineering, United Arab Emirates University, United Arab Emirates \\ ${ }^{3}$ Department of Electrical Power Engineering, Universiti Teknologi Malaysia, Malaysia
}

\begin{tabular}{l}
\hline \hline Article Info \\
\hline Article history: \\
Received Sep 17, 2018 \\
Revised Nov 29, 2018 \\
Accepted Dec 14, 2018
\end{tabular}

Keywords:

Boost rectifier

Lightning search algorithm

Optimisation

PI controller

Synchronous reference frame

\begin{abstract}
This paper proposes a new voltage frequency converter (VFC) that converts both voltage and frequency to the required level of voltage and frequency in low voltage networks used in various countries. The proposed converter could be used as a universal power supply for sensitive AC loads. The converter is composed of, input voltage and frequency detection circuitry, full bridge boost rectifier and a DC to AC inverter. In addition, to improve the feasibility and performance of the converter, synchronous reference based PI (SRFPI) controller is adopted, where the system behaves similar to a DC-DC converter. The parameter selection of PI controller is done using a recent optimisation technique called Lightning Search Algorithm (LSA). The simulation of VFC is conducted in MATLAB/Simulink environment. The simulation results show that LSA based PI controller provides better output voltage regulation with respect to the reference value under various load and input conditions.
\end{abstract}

Copyright (C) 2019 Institute of Advanced Engineering and Science. All rights reserved.

\section{Corresponding Author:}

Hussain Shareef, Department of Electrical Engineering, United Arab Emirates University, Al-Ain, 15551, United Arab Emirates. Email: shareef@uaeu.ac.ae

\section{INTRODUCTION}

Power systems throughout the world today are mainly based on either the U.S. or European standards. Different voltages and frequencies can pose real problems for the equipment designed to operate at specific voltage and frequency. In fact, use of a voltage frequency converter (VFC) is an alternative to overcome these difficulties. Diverse types of VFCs are available now, for example transformer based voltage converters are commonly used for this application. However, it results in increased power loss and makes the system bulky. Hence a transformer-less based VFCs has attracted special attention due its high efficiency, minimised cost and size of the system.

A VFC mainly consists of a rectifier and an inverter for AC-DC and DC-AC operation respectively [1]. The rectifier converts the input voltage into the DC link voltage and inverter performs the conversion of the DC link voltage to a constant load voltage. In addition to the power circuit, feedback control circuit is used to regulate the load voltage to a set reference value. The major challenges in an inverter design are the control of output voltage and current signals regardless of the load type to which it is connected. Numerous control techniques have been documented for controlling typical single phase voltage source inverters that includes LC Resonance control [2], sliding-mode control [3], repetitive control [4] and synchronous reference frame control [5].Among which synchronous reference frame based space vector PWM control, commonly used in three phase inverters are now widely applied in single phase inverters due to its better 
steady state and dynamic performance [6]. Hence, the inverter can be modeled as a DC-DC buck or boost converter.

Previous researches reported in [7], [8] validates that proportional and integral (PI) controller have good control performance during source and load disturbances. Besides, PI controller enables to achieve zero steady-state error at the fundamental frequency of the converter [9]. In a PI controller, finding the gain parameters $K_{p}$ and $K_{i}$ is a complex task to ensure the best performance of overall system. PI controllers can be tuned either manually or using rule-based methods such as Ziegler Nichols technique. But these methods are iterative, time consuming, and sometimes produce large overshoot. Apart from these traditional methods, several intelligent optimisation techniques can be used to solve the complexity in computational procedure in tuning controller parameters so as to achieve an optimal system design [10], [11]. Recently, numerous studies have discussed heuristic optimisation methods that includes genetic algorithm (GA) [12], Particle Swarm Optimisation (PSO) [13], [14] for improving PID controllers. In [15] PSO has been utilised for PI controller optimization in single phase inverters. However, this method fails to provide best pair of control parameters due to early convergence.

Therefore, the aim of this research is to develop a VFC that can convert $120 \mathrm{~V} / 60 \mathrm{~Hz}$ (U.S low voltage standard) to $230 \mathrm{~V} / 50 \mathrm{~Hz}$ (Europe/Asia low voltage standard) and vice versa. Moreover, a heuristic optimisation called Lightning Search Algorithm (LSA) is adopted in tuning PI controller to enhance performance and efficiency of overall system. LSA is a meta heuristics optimisation technique based on the behaviour of lightning. It is used to solve complex problems related to control parameter optimisation [16]. Compared to GA and PSO, it is computationally efficient, simple and has higher convergence rate [17].

The paper is divided as follows: Section 2 describes the proposed topology; section 3 provides the analysis of SRF based PI control system; section 4 gives detailed study of LSA optimisation technique; section 5 represents the simulation results to verify the theoretical discussions regarding output voltage control under varying input and load conditions. Finally section 6 concludes this work.

\section{SYSTEM DESCRIPTION}

The proposed system is depicted in Figure 1. As seen in the Figure, the converter configuration comprises of a full bridge diode rectifier, a conventional boost converter and a single-phase voltage source inverter. A full bridge diode rectifier initially rectifies the supply voltage. In case of converting $120 \mathrm{~V} / 60 \mathrm{~Hz}$ to $230 \mathrm{~V} / 50 \mathrm{~Hz}$, a step up converter is needed to maintain a constant DC link voltage required by the inverter. This can be achieved using a boost converter where the output voltage is regulated by controlling the duty cycle $\mathrm{D}$ of switch $\mathrm{S}_{0}$. For a conventional boost converter, the voltage gain is given by:

$$
\frac{V_{d c}}{V_{i n}}=\frac{1}{1-D}
$$

where $\mathrm{D}$ is the duty cycle, $\mathrm{V}_{\mathrm{dc}}$ is the $\mathrm{DC}$ link voltage and $\mathrm{V}_{\text {in }}$ is the input voltage.

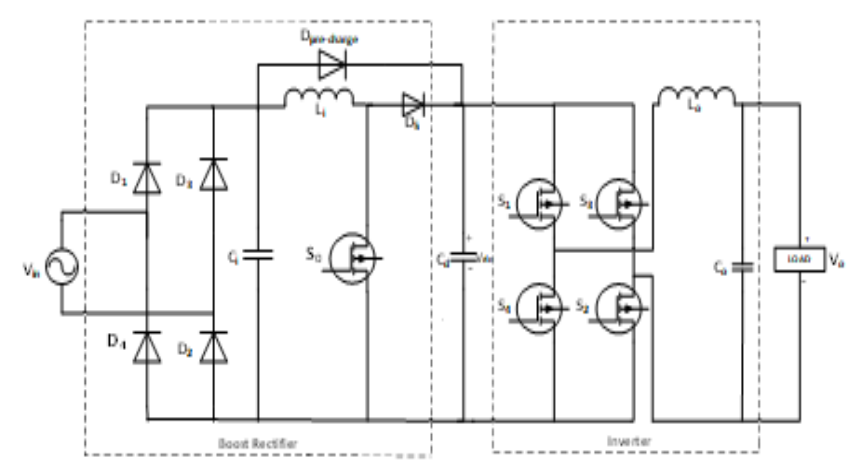

Figure 1. Proposed single phase voltage-frequency converter

To have a smooth continuous input current, the filter inductor $\mathrm{L}_{\mathrm{o}}$ with an appropriate value must be chosen. In addition, a pre-charge diode is kept parallel to the boost inductor to initially charge the DC link capacitance prior to converter start-up. Followed by the boost stage, single phase full bridge inverter convert

Analysis and design of single-phase voltage-frequency converter with optimized PI controller (M. Asna) 
the DC link voltage to pure AC voltage with required frequency using unipolar pulse width modulation (PWM). In unipolar PWM, the gate signals for driving the switching devices are generated by comparing the sinusoidal reference signal with a triangular carrier. Also the amplitude of output voltage and its fundamental frequency is controlled by the reference/modulation signal as per the given relation:

$$
m_{a}=\frac{A_{\text {ref }}}{A_{\text {carrier }}}
$$

where modulation index, $\mathrm{m}_{\mathrm{a}}$ is defined as the ratio of amplitude of reference, $\mathrm{A}_{\mathrm{ref}}$ to amplitude of carrier signal, $\mathrm{A}_{\text {carrier. }}$

Magnitude of output voltage $\mathrm{V}_{\mathrm{o}}$ can be obtained as:

$$
V_{o}=m_{a} * V_{d c}
$$

The low pass LC filter at the output end filters the unwanted voltage and current harmonics generated by the inverter to obtain a pure sinusoidal output voltage waveform.

\section{SYNCHRONOUS REFERENCE FRAME BASED PI CONTROLLER}

Synchronous reference frame (SRF) control in three phase system requires representation of three phase variables as two equivalent orthogonal vectors. However, it is hard to adopt this technique in single phase converters since it requires at least two orthogonal vectors from a single phase quantity. To generate orthogonal vectors, different techniques can be used [18]-[20]. In this study, the most common method is used, in which a time delay block introduces a phase shift of $90^{\circ}$ with respect to fundamental frequency of reference signal. Once, the two orthogonal phases are generated, the converter can be modelled in synchronous reference frame. Using (4), orthogonal signals obtained undergoes Park Transformation (DQ Transformation) so as to obtain signals in synchronous reference frame.

$$
\left[\begin{array}{l}
V_{d} \\
V_{q}
\end{array}\right]=\left[\begin{array}{cc}
\cos \omega t & \sin \omega t \\
-\sin \omega t & \cos \omega t
\end{array}\right]\left[\begin{array}{l}
V_{\alpha} \\
V_{\beta}
\end{array}\right]
$$

Therefore, the AC quantities in stationary reference frame become DC vectors in rotating $\alpha \beta$ reference frame. Thus the controller design becomes as simple as DC-DC converter.

\section{OPTIMISATION OF PI CONTROLLER}

Multiloop control system can effectively reduce output voltage variation and provide better transient response under linear and non-linear load conditions [21].

As shown in Figure 2, inverter output voltage $V_{o}$ and inductor current $I_{0}$ will form an outer voltage loop and inner current loop respectively, each governed by a PI controller for minimising steady state error with respect to reference signal. The voltage reference would determine the desired output voltage required whereas current reference is determined by outer voltage loop.

It is necessary to tune PI controller parameters in order to obtain robust performance of the proposed converter over a wide range of operating conditions. Without the proper selection of PI constants, system behaviour becomes unstable. Besides the classical method of tuning, a better way to tune PI controller is to use the optimisation techniques discussed in literature. In this paper, a meta heuristic optimisation technique called Lightning Search Algorithm (LSA) is adopted for tuning voltage and current PI controllers.

Int J Pow Elec \& Dri Syst, Vol. 10, No. 1, March 2019：522 - 529 


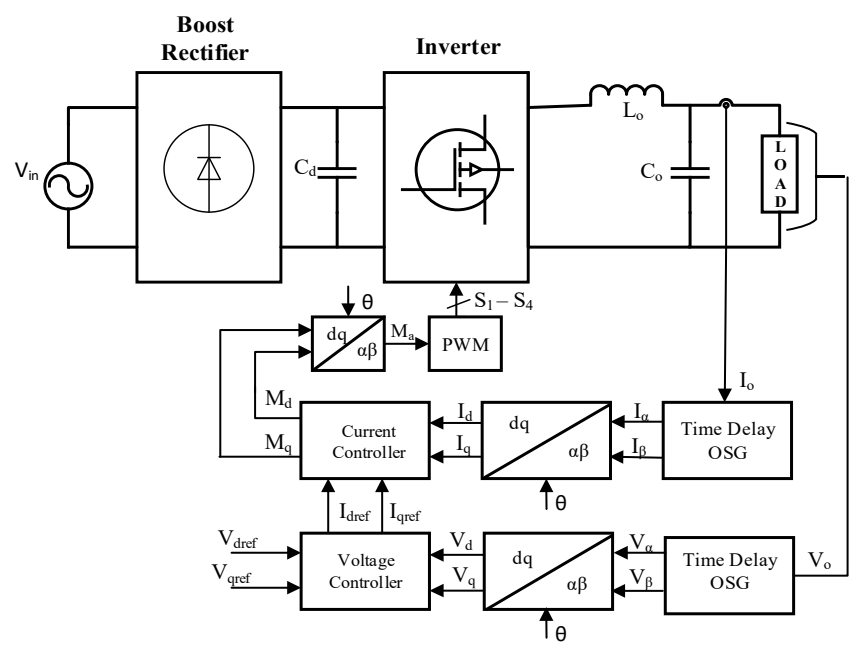

Figure 2. Synchronous reference frame control structure for proposed converter

\subsection{Concept of LSA}

LSA is a novel optimisation techniques based on the phenomenon of lightning. It adopts the concept of step leader propagation using the fast particles called projectiles, forming a binary tree structure of step leader. Three types of projectiles used are (a) the transition projectiles that create the first leader population (b) the space projectiles that try to become the leader and (c) the lead projectile that represents the projectile found from the best positioned step leaders. The detailed LSA algorithm steps are given in [17].

\subsection{Problem Description}

In the controller structure shown in Figure 2, error in dq voltages and current is fed to respective PI controllers. Hence four PI controllers need to be tuned by LSA optimisation to obtain better results. The key elements required for solving any optimisation problem are

a. Input Vector

b. Objective Function

c. Optimisation Constraints

Steps involving in LSA are stated as follows:

a. Set the LSA parameters namely number of iterations $\mathrm{T}$, population size $\mathrm{N}$, dimension of input vector $\mathrm{D}$ and channel time.

b. Initialise the projectile vector containing step leaders that need to be optimised. Each particle in the population corresponds to PI constants $K_{p}$ and $K_{i}$. The expression below represents the input vector, $Z_{i j}$.

$$
Z_{i j}=\left[\begin{array}{ccc}
X_{11} & \cdots & X_{1 n} \\
\vdots & \ddots & \vdots \\
X_{m 1} & \cdots & X_{m n}
\end{array}\right]
$$

where $\mathrm{a}<\mathrm{X}_{\mathrm{ij}}<\mathrm{b}$, in which $\mathrm{a}$ and $\mathrm{b}$ are lower and upper bounds that represents the optimisation constraints.

c. Calculate the fitness value for each particle in the population using the objective function defined in (6). In SRFPI controller, RMSE of inverter output voltage is taken as the objective function to measure the performance index.

$$
R M S E=\sqrt{\frac{1}{n} \sum\left(V_{\text {dref }}-V_{d}\right)^{2}}
$$

where $V_{\text {dref }}$ is the reference voltage, $V_{d}$ is the measured output voltage and $n$ is the number of samples.

d. Modify the initial input matrix, $Z_{\mathrm{ij}}$ in terms of direction, position and value as per the relation,

$$
P_{i} S_{\text {new }}=P_{i}^{S} \pm \text { exprand }\left(\mu_{i}\right)
$$

Analysis and design of single-phase voltage-frequency converter with optimized PI controller (M. Asna) 
$P_{\text {new }}=P^{L} \pm$ norm rand $\left(\mu L, \sigma_{L}\right)$

where $P_{i}^{S}$ new is the new space particle

$\mathrm{P}_{i}^{\mathrm{S}}$ represents old space particle

$\mathrm{P}^{\mathrm{L}}{ }_{\text {new }}$ is the new lead particle

$\mathrm{P}^{\mathrm{L}}$ is the old lead particle

$\mu$ is shaping factor

$\sigma$ is the scale factor

e. Repeat steps 3 and 4 until the iteration count reaches maximum value.

\section{SIMULATION AND RESULTS}

To validate the operation of proposed voltage frequency converter, the system is built in MATLAB Simulink environment as shown in Figure 3.

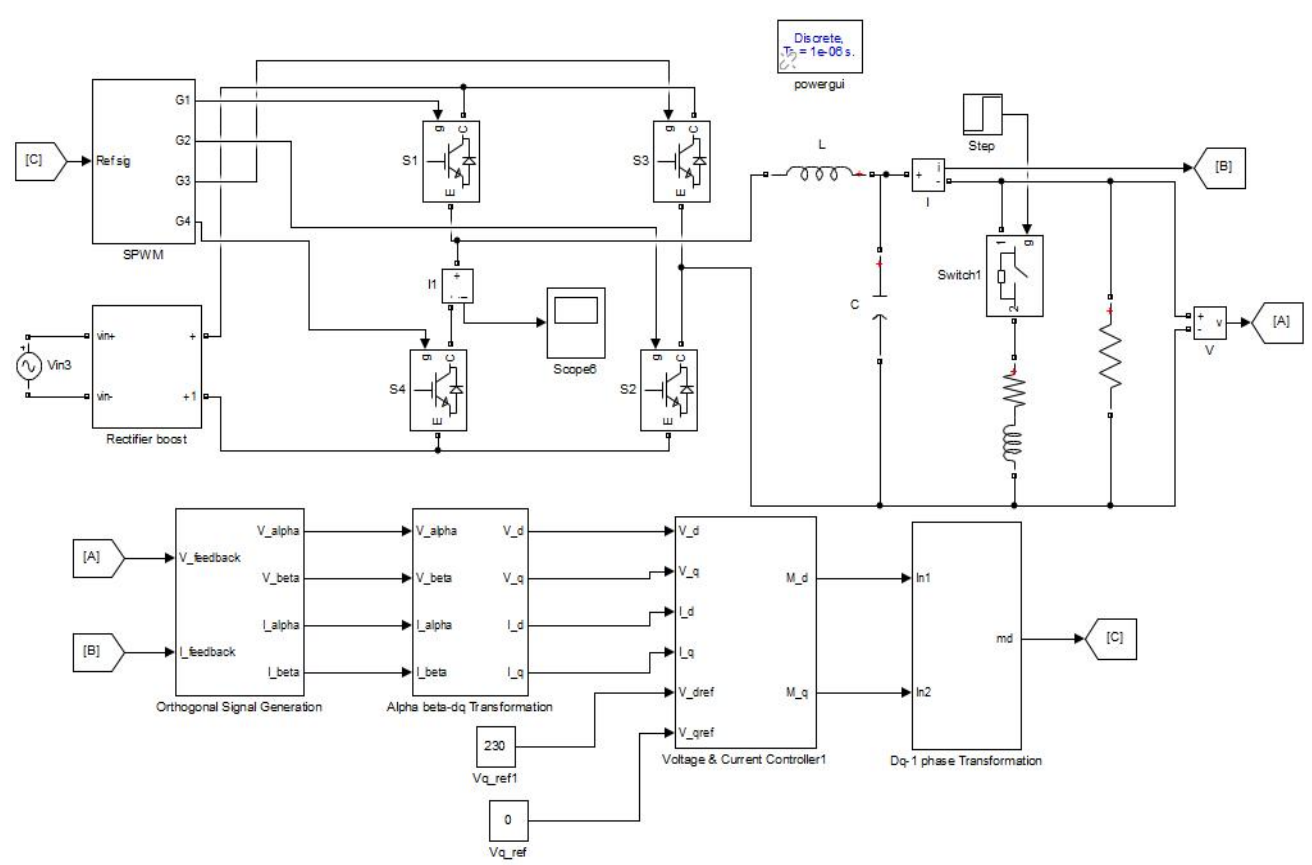

Figure 3. Simulation model of voltage frequency converter

The simulation has been carried out for $0.3 \mathrm{~s}$ at a sampling time of $1 \mu \mathrm{s}$. The specifications for the simulation are listed on the Table 1.

Table 1. Simulation parameters of voltage frequency converter

\begin{tabular}{ll}
\hline Parameters & Values \\
\hline Input Voltage, $\mathrm{V}_{\mathrm{i}}$ & $120 \mathrm{~V}_{\text {rms }}$ \\
Output Voltage, $\mathrm{V}_{\mathrm{o}}$ & $230 \mathrm{~V}_{\text {rms }}$ \\
Output Power & $800 \mathrm{~W}$ \\
DC Link Voltage, $\mathrm{V}_{\mathrm{dc}}$ & $350 \mathrm{~V}$ \\
Input Inductance, $\mathrm{L}_{\mathrm{i}}$ & $6 \mathrm{mH}$ \\
DC Link Capacitance, $\mathrm{C}_{\mathrm{d}}$ & $2.5 \mathrm{mF}$ \\
Filter Inductance, $\mathrm{L}_{\mathrm{o}}$ & $3.8 \mathrm{mH}$ \\
Filter Capacitance, $\mathrm{C}_{\mathrm{o}}$ & $8 \mu \mathrm{F}$ \\
\hline
\end{tabular}


Optimal parameters for PI controller using LSA is implemented with MATLAB mfile code and it is linked with Simulink. Parameters of LSA for simulation are listed below.

Number of iterations, $\mathrm{T}=20$

Population size, $\mathrm{N}=10$

Number of dimensions, $\mathrm{D}=8$

The optimised value of $K_{p}$ and $K_{i}$ obtained after simulation are tabulated in Table 2.

Table 2. PI Parameters

\begin{tabular}{ccc}
\hline PI Controller & $\mathrm{K}_{\mathrm{p}}$ & $\mathrm{K}_{\mathrm{i}}$ \\
\hline PID 1 & 91.7 & 51.1 \\
PID 2 & 93.7 & 9.3 \\
PID 3 & 80.5 & 20.4 \\
PID 4 & 78.4 & 28.1 \\
\hline
\end{tabular}

Figure 4 depicts the convergence curve for optimisation in which root mean square error has reduced to nearly zero value after performing 20 iterations.

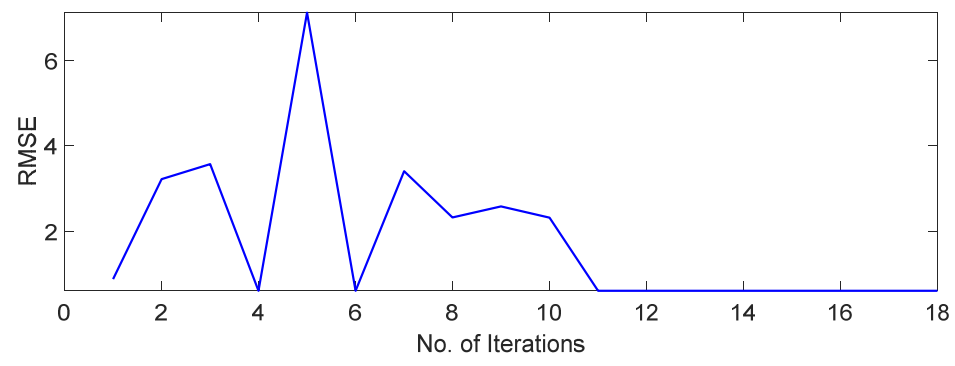

Figure 4. Performance error curve

To examine the performance of VFC with optimised PI controller under varying load and input conditions, the following situations were analysed.

a. The load has varied from R to RL load, the output voltage and current response under this condition is plotted in Figure 5. The reference voltage is taken as $230 \mathrm{~V} / 50 \mathrm{~Hz}$. It is evident from the waveforms that output voltage follows reference value $(230 \mathrm{~V} / 50 \mathrm{~Hz})$ exactly after few milliseconds. Besides the waveform also shows the change in the power factor after an additional RL load is connected at 0.1 second.

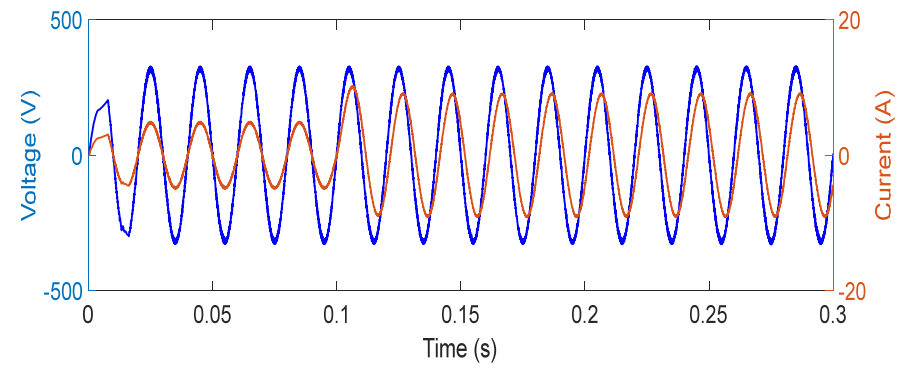

Figure 5. Effect of load changes on output voltage and current waveform of proposed VFC for a step change from $R$ to RL load

b. The effect of input voltage on the proposed converter is illustrated in Figure 6. In this case, the input voltage, $\mathrm{V}_{\text {in }}$ is changed from $120 \mathrm{~V} / 60 \mathrm{~Hz}$ to $230 \mathrm{~V} / 50 \mathrm{~Hz}$ as shown in Figure $6 \mathrm{a}$ for R load. Initially the

Analysis and design of single-phase voltage-frequency converter with optimized PI controller (M. Asna) 
reference out voltage is set as $230 \mathrm{~V} / 50 \mathrm{~Hz}$, and the output voltage clearly tracks the reference voltage as depicted in Figure 6c. When $\mathrm{V}_{\text {in }}$ is changed to $230 \mathrm{~V} / 50 \mathrm{~Hz}$ after $0.1 \mathrm{~s}$, the output voltage settles to the new reference value, $120 \mathrm{~V} / 50 \mathrm{~Hz}$ as shown in Figure 6c. DC link voltage is regulated at a reference value of $350 \mathrm{~V}$ with a slight variation, as depicted in Figure $6 \mathrm{~b}$. Therefore, from Figure 6 it is clear that synchronous reference frame PI controller succeeds in regulating the output voltage for variation in input voltage which is commonly found as the standard voltage at mains low voltage supply in various countries.

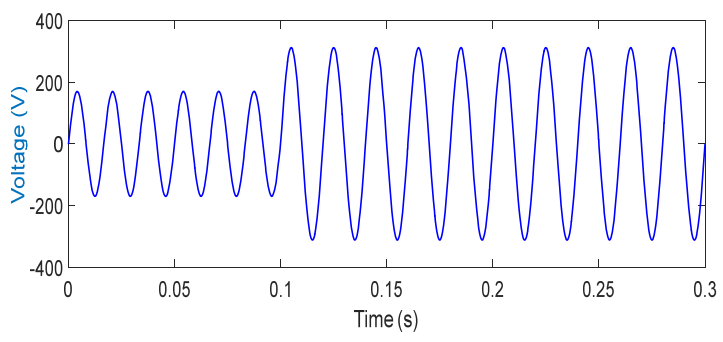

(a)

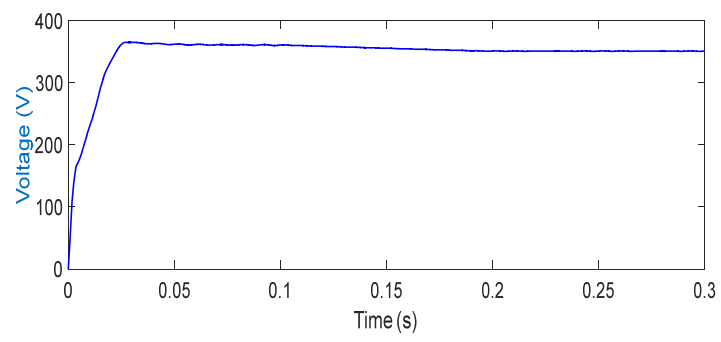

(b)

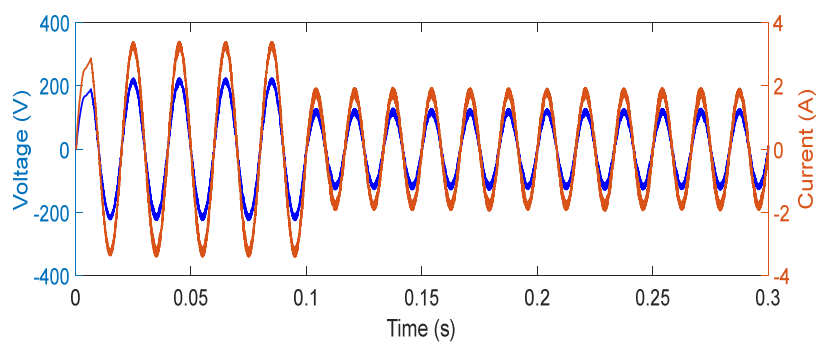

(c)

Figure 6. Effect of input voltage variation on proposed VFC. (a) Input voltage waveform (b) DC link voltage (c) Output voltage response

\section{CONCLUSION}

This paper presented a voltage frequency converter design that could be used in protable low voltage VFC. It employs synchronous reference frame based PI controller for automatically regulating the output voltage in accordance with the reference voltage. LSA based PI controller tuning is adopted to enhance the performance of the proposed converter. In addition, simulation results successfully support the ability of the converter to optimally regulate the output voltage under varying load conditions and input conditions.

\section{ACKNOWLEDGEMENTS}

This work was supported by the United Arab Emirates University (UAEU) under Grant 31N34816_7_SURE+2018

\section{REFERENCES}

[1] P. Ziogas, et al., "Optimum system design of a three phase rectifier-inverter type of frequency changer", IEEE Transactions on Industrial Applications, vol. IA-21, no. 5, pp. 1215-1225, 1985.

[2] J. Argo, et al., "A control method for single phase PWM inverters,"Proceedings of the International Conference on Power Electronics and Drive Systems, pp. 282-285, 2001.

[3] A. Abrishamifar, et al., "Fixed switching frequency sliding mode control for single-phase unipolar inverters", IEEE Transactions on Power Electronics, vol. 27, no. 5, pp. 2507-2514, 2012.

[4] K. Zhou, et al., "Zero-phase odd-harmonic repetitive controller for a single-phase PWM inverter", IEEE Transactions on Power Electronics, vol. 21, no. 1, pp. 193-201, Jan. 2006. 
[5] M. J. Ryan and R. D. Lorenz, "A synchronous-frame controller for a single-phase sine wave inverter", Proceedings of IEEE APEC, pp. 813-819, Feb. 1997.

[6] A. Roshan, et al., "A D-Q frame controller for a full-bridge single phase inverter used in small distributed power generation systems," Proceedings of IEEE APEC, Feb. 2007, pp. 641-647.

[7] L. Yun, et al., "PID control system analysis and design," Control Systems, IEEE, vol.26, pp. 32-41, 2006.

[8] R. Ortega, et al., "Control techniques for reduction of the total harmonic distortion in voltage applied to a singlephase inverter with nonlinear loads: Review." Renewable and Sustainable Energy Reviews, vol. 16, no. 3, pp. 1754-1761,2012.

[9] A. I. Maswood, and E. Al-Ammar, "Analysis of a PWM Voltage Source Inverter with PI Controller under Nonideal conditions", IEEE Conference IPEC, pp.193-198, 2010.

[10] J. H. Zhang, et al., "Self-organizing genetic algorithm based tuning of PID controllers", Information. Sciences, vol. 179, no. 7, pp. 1007-1018, 2009.

[11] A. Khateb, et al., "Optimized PID Controller for Both Single Phase Inverter and MPPT SEPIC DC/DC Converter of PV Module", IEEE International Electric Machines and Drives Conference (IEMDC), pp. 1036-1041, 2011.

[12] Arunkumar G, et al., "Parameter optimization of three phase boost inverter using genetic algorithm for linear loads" Energy Proceedings, vol. 90, pp. 559-565,2016.

[13] T. H. Kim, et al., "Robust PID controller tuning based on the constrained particle swarm optimization"Automatica, vol. 44, no. 4, pp. 1104-1110, 2008.

[14] M. Abdolrasol, et al., "PSO Optimization For Solar System Inverter Controller And Comparison Between Two Controller Techniques ", Jurnal Teknologi. 78. 10.11113/jt.v78.8904,2016.

[15] A. Althobaiti, et al., "Control parameters optimization of a three-phase grid-connected inverter using particle swarm optimization", International Conference on Power Electronics, Machines and Drives (PEMD), 2016.

[16] H. Shareef, et al., "A novel approach for fuzzy logic PV inverter controller optimization using lightning search algorithm", Neurocomputing, vol. 168, pp. 435-453, 2015.

[17] H. Shareef, et al., "Lightning search algorithm", Applications of Soft Computing, Journal, vol. 36, pp. 315-333, 2015.

[18] S.M. Silva, et al., "Performance evaluation of PLL algorithms for single phase grid-connected systems, IEEE Industry Applications Conference, vol.4, pp. 2259 - 2263,2004.

[19] M. Ciobotaru, et al., "A New Single-Phase PLL Structure Based on Second Order Generalized Integrator", Power Electronics Specialists Conference, pp. 1-6, 2006.

[20] C. Blanco, et al., "Quadrature Signal Generator based on All-Pass Filter for Single-Phase Synchronization"

[21] N. M. Abdel-Rahim and J. E. Quaicoe, "Analysis and design of a multiple feedback loop control strategy for singlephase voltage-source UPS inverters," IEEE Transactions on Power Electronics, vol. 11, pp. 532-541, July 1996. 